\title{
Schopenhauer e os Valores da Experiência Estética, de Bart Vandenabeele
}

\author{
VANDENABEELE, BART Schopenhuaer on the Values of Aesthetic \\ Experience $^{1}$
}

\section{Renata Covali Cairolli Achlei ${ }^{1}$ Luan Corrêa da Silva $^{2}$}

Resumo: Neste ensaio argumento que a visão de Schopenhauer dos sentimentos estéticos do belo e do sublime mostra como uma interpretação "dialética" que homogeneíza ambos os conceitos estéticos e reduz as discrepâncias entre eles a meras diferenças quantitativas é falha. Minha análise crítica revela algumas tensões importantes tanto na própria teoria estética de Schopenhauer - que, em última instância, não é bem sucedida em fundir as abordagens de Platão e Kant - quanto na interpretação que injustamente reduz o valor da experiência estética a um mero estágio preliminar da salvação ética destituída de vontade.

Palavras-chave: Belo; Sublime; Schopenhauer

A Arte não nos machuca. As lágrimas que dividimos em um espetáculo são um tipo de emoção requintada e estéril a qual é a função da arte despertar. Choramos, mas não estamos feridos.

Oscar Wilde

The Critic as Artist

$\mathrm{Na}$ interpretação tradicional da teoria estética schopenhaueriana prevalece o pensamento de que o prazer estético está enraizado na libertação do sujeito das garras da vontade cega, e que tal prazer (negativo) de libertação nos prepara para a libertação ética permanente do querer que, de acordo com Schopenhauer, é o objetivo de uma vida verdadeiramente ética e ascética. Portanto, a estética de Schopenhauer é frequentemente reduzida à um mero estágio preliminar de uma ética metafísica. Gostaria de começar por desafiar esse ponto de vista.

É claro que tal interpretação "dialética" ${ }^{2}$ contém uma certa plausibilidade, e o próprio Schopenhauer a apoia com frequência. No entanto, pode-se formular um questionamento,

\footnotetext{
${ }^{1}$ Tradução do artigo originalmente publicado em The Southern Journal of Philosophy, Vol. XLV, 2007, pp. 565582.

${ }^{2}$ Para essa interpretação dominante ver, por exemplo, D.W. Hamlyn, Schopenhauer (London: Routledge and Keagan Paul, 1980); A. Philonenko, Une philosophie de la tragédie (Paris: Vrin, 1980); T. Eagleton, The Ideology
}

1Doutoranda em Filosofia pela Universidade Federal do Paraná, Curitiba, PR. E-mail: achleirenata@gmail.com

ORCID: https://orcid.org/o000-0001-9933-1616

2Doutor em Filosofia pela Universidade Federal de Santa Catarina, Florianópolis, SC. Professor substituto da Universidade Federal do Paraná, Curitiba, PR. E-mail: luanbettiol@gmail.com ORCID: https://orcid.org/oooo-0001-5913-6744 
afirmando que há muito mais do que uma preparação para uma ética ascética na estética schopenhaueriana. A descrição de Schopenhauer do caráter positivo do prazer estético e do significado específico do sentimento sublime necessita de uma interpretação de sua estética mais sutil e menos reducionista. Se não ignorarmos a importância do prazer estético e se investigarmos suas variações específicas, diversas tensões interessantes, que são negligenciadas com frequência na interpretação dialética, se revelarão.

Mas não conseguiremos uma visão clara sobre o tema do prazer estético e suas variações se não prestarmos suficiente atenção à questão epistemológica mais importante da estética de Schopenhauer: como podemos perceber a essência das coisas 3 ? Apenas depois de respondida essa questão poderemos indagar sobre a especificidade do prazer estético no belo e no sublime. Aqui devo discutir alguns problemas da interpretação dialética predominante e, também, iluminar diversas tensões nas considerações do próprio Schopenhauer.

Após uma análise acerca do caráter positivo do prazer estético e da importância do sentimento do belo, tentarei mostrar que há uma importante ambivalência na análise schopenhaueriana do sublime. Por um lado, ele considera o sublime uma espécie de sentimento intenso do belo e até mesmo esboça exemplos de transição do belo para o sublime; por outro lado, em sua análise de inspiração kantiana, o sublime é tido como qualitativamente diferente do sentimento do belo. $\mathrm{O}$ que ainda pode ser sentido como uma breve promessa de unidade e harmonia (até mesmo felicidade) no sentimento do belo será exposto como ilusório na aguda "mistura" entre prazer e dor que é o sentimento do sublime. A teoria schopenhaueriana do sublime talvez funcione como uma dobradiça aporética em sua filosofia, a qual (a despeito das esperanças de Schopenhauer) exclui uma transição fácil para a ética destituída de vontade da resignação. Mas antes de buscar descobrir a importância do sublime, façamos algumas observações de natureza mais geral ${ }^{4}$.

\section{Percepção Estética}

Schopenhauer argumenta que o fenômeno empírico tem um lado obscuro: "algo" que só pode ser percebido nas sensações internas de nosso próprio corpo se retira de nossa percepção empírica. Quando nosso corpo se move, nossos movimentos são acompanhados por uma sensação desses movimentos corporais e do que os motiva. O objeto dessa sensação é o que Schopenhauer chama de vontade individual. O corpo é a fronteira entre o mundo de nossa vontade e o mundo de nossas representações. O entrelaçamento da vontade e da representação que é anunciado no título da obra magna de Schopenhauer, O Mundo como Vontade e Representação, encontra seu mais íntimo emaranhado no corpo.

\footnotetext{
of the Aesthetic (Oxford: Blackwell, 1990), e também (embora em menor grau) B. Neymeyr, Ästhetische Autonomie als Abnormität (Berlin/New York: Walter de Gruyter, 1996).

3 Neste ensaio pretendo desconsiderar a teoria schopenhaueriana da música, que contorna as Ideias platônicas. Ver The Blossom of Life: Aesthetics and Ethics in Schopenhauer's Philosophy, minha próxima publicação.

4 Utilizo das seguintes abreviações nesse ensaio:

- WWR I, II: The World as Will and Representation, 2 vols., trad. E. F. J. Payne, (New York: Dover Publications, 1966)

- FR: The Fourfold Root of the Principle of Sufficient Reason, trad. E. F. J. Payne (La Salle: Open Court, 1997)

- PP I, II: Parerga and Paralipomena, 2 vols., trad. E. F. J. Payne (Oxford: Clarendon Press, 1974)

- HN I, II, III, IV, V: Der handschriftliche Nachlass, 5 Bäude, ed. A. Hübscher (Frankfurt am Main: Waldemar Kramer, 1975-1996)

- BM: On the Basis of Morality, trad. E. F. J. Payne, with an introduction by David E. Cartwright (Providence: Berghahn Books, 1995)
} 
Consequentemente, Schopenhauer com frequência chama o corpo de objeto imediato ou objetidade imediata (Objektität) da vontade, porque nós temos uma afecção de nosso próprio corpo que não é uma representação espacialmente ordenada5. Essa "compreensão" afetiva - as sensações de dor e desejo, por exemplo - é imediata, uma vez que é de natureza puramente temporal e não é determinada por espaço e causalidade ${ }^{6}$. Esse conhecimento duplo que temos de nosso próprio corpo oferece uma visão de suas atividades e seus movimentos com base em seus motivos. Nós não possuímos esse tipo de conhecimento de outros objetos reais?.

A hipótese metafísica de Schopenhauer é que a realidade como um todo é, em última instância, nada menos do que a perceptível manifestação de uma vontade cega e irracional. Desde que estamos, como indivíduos, amarrados ao tempo e ao espaço, e como é necessário que se considere o núcleo da realidade como uma vontade não-empiricamente apreensível, inconsciente e irracional, é impossível que um indivíduo tenha conhecimento imediato da vontade. A vontade é o núcleo imperceptível do fenômeno, assim como os movimentos corporais são exponentes perceptíveis dos atos imperceptíveis da vontade.

Todo ato verdadeiro de sua vontade é imediata e inevitavelmente um movimento de seu corpo; ... A ação do corpo nada mais é do que o ato da vontade objetificado, i.e., traduzido em percepção ${ }^{8}$. (WWR I, § 18, 100)

Então, uma rota peculiar se faz necessária, que ofereça uma visão transcendental daquilo que estará sempre escondido do ponto de vista empírico. Esta rota se desenvolve através da percepção estética ou intuição (Anschauung). A intuição estética possui importância cognitiva na filosofia de Schopenhauer: ela possibilita que se obtenha informações sobre algo que não pode ser inteligível de forma empírica ou por conceitos lógicos. A percepção estética oferece um tipo de entendimento notável que não pode ser traduzido em conceitos determinados. Tal percepção estética não deve ser identificada como uma mera intuição distante e mística de um objeto esotérico qualquer. Schopenhauer situa explicitamente o místico no domínio da religião e da ética, conectando-o com a resignação (Quietismus) e o asceticismo (Askesis)9. A percepção estética é uma forma peculiar de se experienciar coisas na qual nossas capacidades cognitivas funcionam de uma maneira incomum ${ }^{10}$.

\footnotetext{
${ }^{5}$ Para um estudo comparativo detalhado sobre o corpo em Schopenhauer e Fichte, ver H. Schöndorf, Der Leib im Denken Schopenhauers und Fichtes (München: Johannes Berchmans, 1982). O termo objeto imediato (unmittelbares Objekt), que Schopenhauer raramente utiliza após 1813, também aparece em Schelling e Fichte. Sobre o corpo como Objektität des Willens (objetidade da vontade), ver WWR I, § 20-21, § 48, § 6o e WWR II, cap. 41.

${ }^{6}$ WWR I, § 18, 101: "Cada verdadeiro, genuíno e imediato ato da vontade é também de uma só vez e diretamente um ato manifesto do corpo; e de modo correspondente, por outro lado, cada ação [Einwirkung] do corpo é também de uma só vez e diretamente uma reação da vontade".

7 Ver $W W R$ I, § 19.

${ }^{8}$ A vontade não é uma função do intelecto. Ao contrário, o intelecto (e sua manifestação física: o cérebro) é uma função da vontade. O intelecto é, na verdade, terciário: ele pressupõe o organismo, e o organismo pressupõe a vontade. Ver também WWR II, 278: "Longe de ser absolutamente a primeira coisa (como pensava Fichte, por exemplo) é, no fundo, terciária, uma vez que pressupõe o organismo, e o organismo pressupõe a vontade".

9 Ver WWR II, 613: "Quietismo, i.e., o desistir de todo o querer, ascese, i.e., mortificação intencional da própria vontade, e misticismo, i.e., a consciência da identidade do próprio sujeito com todas as outras coisas, ou com o núcleo do mundo, estão na mais restrita conexão".

${ }^{10}$ G. Dickie, Introduction to Aesthetics. An Analytic Approach (New York/Oxford: Oxford University Press, 1997), 25: "Schopenhauer conserva de Kant apenas a noção de que as faculdades cognitivas operam de maneira incomum”. Que esta seria a única noção que ele conserva de Kant é altamente questionável.
} 
Uma experiência estética consiste em duas partes inseparáveis: a autoconsciência do espectador, não como indivíduo, mas como puro sujeito do conhecer desprovido de vontade, e o objeto, não como um objeto particular, mas como Ideia (platônica) ${ }^{11}$. $\mathrm{O}$ primeiro reforça o desinteresse de toda percepção estética: ${ }^{12}$

Quando uma causa externa ou uma disposição interna de repente nos eleva para longe do fluxo do querer, e retira o conhecimento da escravidão da vontade, a atenção não é mais dirigida aos motivos do querer, mas, sim, compreende as coisas livres de sua relação com ele. Portanto, considera-se as coisas sem interesse, sem subjetividade, de forma puramente objetiva. (...) Então, de uma só vez, a paz, sempre buscada mas sempre fugidia naquele caminho do querer, se nos apresenta espontaneamente, e tudo está bem conosco. (WWR I, § 38,196$)$.

Ademais, Schopenhauer acrescenta, "estamos completamente satisfeitos com a impressão que nos causa um objeto de arte somente quando ele transmite algo que, a despeito de toda nossa reflexão sobre ele, não conseguimos reduzir a um conceito" (WWR II, 409). A transição para um conceito claramente definido é, obviamente, segundo Schopenhauer, uma degradação. Uma intuição estética de forma alguma contribui para o conhecimento conceitual, mas, sim, isola o objeto percebido de suas conexões meramente empíricas e práticas através de sua percepção como um objeto ideal. Esse tipo de percepção é particularmente o trabalho da imaginação e é uma libertação das limitações impostas pelo princípio de razão suficiente que domina o raciocínio lógico.

É crucial para um entendimento apropriado do que Schopenhauer quer dizer exatamente com a intuição estética a importante distinção entre conceito e Ideia. Schopenhauer insiste com frequência que conceito e Ideia se separam por milhas de distância.

O conceito é abstrato, discursivo, completamente indeterminado em sua esfera, determinado apenas por seus próprios limites, apreensível e inteligível apenas por aquele que possui a faculdade da razão, comunicável por palavras sem qualquer outro tipo de assistência, totalmente esgotado em sua definição. A Ideia, por outro lado, definível talvez como a representante adequada do conceito, é absolutamente perceptiva (anschaulich), e embora represente um número infinito de coisas individuais, ainda assim é completamente definida. Nunca é conhecida dessa forma pelo indivíduo... (WWR I, § 49, 233-34).

Apesar do importante papel epistêmico da contemplação livre de vontade, não pode haver dúvidas de que na intuição estética é percebida uma Ideia e não um conceito. A intuição de uma Ideia não nos oferece conhecimento abstrato. A. L. Cothey adequadamente chama essa atividade estética de "contemplação perceptiva"13. Quando uma Ideia é intuída, a percepção de um objeto particular não termina: ganha-se intuição de tal Ideia na e através da percepção de um fenômeno particular ${ }^{14}$. Schopenhauer insiste fortemente nessa diferença

\footnotetext{
${ }^{11}$ Ver WWR I, § 38, 195: "No modo de apreensão estético encontramos duas partes constituintes inseparáveis: a saber, o conhecimento do objeto não como uma coisa individual, mas como Ideia platônica, em outras palavras, como a forma permanente de toda a espécie dessa coisa; e a autoconsciência do sujeito que conhece, não como indivíduo, mas como puro sujeito do conhecer desprovido de vontade".

${ }^{12}$ Ver meu "On the Notion of 'Disinterestedness': Kant, Lyotard e Schopenhauer”, Journal of the History of Ideas 62 (2001): 705-20.

${ }^{13}$ A. L. Cothey, The Nature of Art, (Londres: Routledge, 1990), 75.

${ }^{14}$ P. Gardiner, Schopenhauer (Harmondsworth: Penguin Books, 1971), 206: “consciência e compreensão da Ideia nos e através dos fenômenos individuais da experiência cotidiana”.
} 
entre conceitos e Ideias. Ideias só atraem aquele que se eleva de todo desejar individual e que se tornou puro sujeito do conhecer. $\mathrm{O}$ ataque contundente de Schopenhauer às artes alegóricas e didáticas levanta algumas questões no que se refere ao status das Ideias (platônicas) em sua teoria ${ }^{15}$. Que a teoria das Ideias (platônicas) tenha sido introduzida ad hoc, como sustenta Bryan $\mathrm{Magee}^{16}$, é uma afirmação definitivamente falsa. Por um lado, Schopenhauer repete regularmente que ele oferece a única interpretação correta da teoria das Ideias de Platão, mas, por outro lado, a teoria de Schopenhauer diverge de Platão em diversos pontos cruciais. O próprio Schopenhauer aponta para este fato com frequência ${ }^{17}$. Ele descreve as Ideias como moldes em que a caótica vontade primordial se recolhe antes de se dispersar em incontáveis fenômenos que constituem o mundo como representação. Conceitos são unidades que podem ser coletadas por meio da capacidade de abstração da razão. Ideias são unidades que se tornaram múltiplas devido às formas do espaço e tempo de nossa apreensão intuitiva (intuitive Apprehension) ${ }^{18}$. Elas são a "gramática profunda" pela qual a coisa-em-si se expressa nas estruturas de superfície das aparências fenomênicas.

Além dessa inserção de uma metafísica da vontade, há diversos outros problemas com o platonismo de Schopenhauer ${ }^{19}$, mas não tratarei disso aqui. Quero, no entanto, enfatizar algumas similaridades notáveis com as chamadas Ideias estéticas que Kant menciona na Crítica da Faculdade de Julgar (especialmente nos §49 e §57). A teoria kantiana das Ideias estéticas foi provavelmente um impulso para o papel das Ideias na teoria de Schopenhauer ${ }^{20}$, mas ainda nos falta uma literatura que nos ofereça um comparativo

\footnotetext{
${ }^{15}$ Para seu ataque às alegorias, ver $W W R$ I, $\S 50,237-42$, e $W W R$ II, 422-23.

${ }^{16}$ Ver B. Magee, The Philosophy of Schopenhauer (Oxford, Clarendon Press, 1997), 239: "Na primeira edição de O Mundo como Vontade e Representação Ideias platônicas são introduzidas somente após três quartos da exposição de Schopenhauer de sua epistemologia e ontologia - onde elas (as Ideias), repentina e desconcertantemente, reivindicam uma função fundamental de todo o quadro explicativo. Não posso evitar a suspeita de que elas foram introduzidas ad hoc neste ponto e, posteriormente, acabaram por fugir ao controle". As Ideias platônicas já aparecem nas primeiras notas feitas por Schopenhauer. Ver $H N$ I, 11, 30, 56, 76, 117, 131, 132, 200 etc. Ver também $F R \S 39$, nota de rodapé 4, p. 206.

${ }_{17}$ Ver, por exemplo, WWR I, § 41, 209-12, e WWR I, § 49, 233.

${ }^{18}$ WWR I, § 49, 234-35: "A Ideia é a unidade que se tornou pluralidade por conta das formas do espaço e tempo de nossa apreensão intuitiva. O conceito, por outro lado, é a unidade mais uma vez produzida a partir da pluralidade por meio da abstração através de nossa faculdade da razão; esta pode ser descrita como unitas post rem, e aquela como unitas ante rem."

19 Existe uma vasta literatura a respeito do platonismo de Schopenhauer. Para citar algumas fontes interessantes: James D. Chansky, "Schopenhauer and Platonic Ideas: a Groundwork for an Aesthetic Metaphysics", in: E. von der Luft, Schopenhauer: New Essays in Honor of his $200^{\text {th }}$ Birthday (Lewiston: Edwin Mellen Press, 1988), 67-81; C. Foster, "Ideas and Imagination. Schopenhauer on the Proper Foundation of Art", in: C. Janaway, The Cambridge Companion to Schopenhauer (Cambridge: Cambridge University Press, 1999), 213-51; P. Gardiner, Schopenhauer (Harmondsworth: Penguin, 1967), 203-19; P. Guyer, "Pleasure and Knowledge in Schopenhauer's Aesthetics", in: D. Jacquette, Schopenhauer, Philosophy, and the Arts (Cambridge: Cambridge University Press, 1996), 109-32 [republicado in: P. Guyer, Values of Beauty (Cambridge: Cambridge University Press, 2005), 265-88]; D. W. Hamlyn, Schopenhauer, 103-22; H. Hein, "Schopenhauer and Platonic Ideas", Journal of the History of Philosophy 4 (1966): 133-44; C. Janaway, Schopenhauer (Oxford: Oxford University Press, 1994), 61-70; Y. Kamata, "Platonische Idee und die anschauliche Welt bei Schopenhauer", Schoenhauer-Jahrbuch 7o (1989): 84-93; Magee, The Philosophy of Schopenhauer, $165-69$ and 239-40; S. G. Neeley, "Schopenhauer and the Platonic Ideas": a Reconsideration", Idealistic Studies 30 (2000): 121-48; C. Rosset, L'esthétique de Schopenhauer (Paris: P.U.F., 1969), 33-39; T. G. Taylor, "Platonic Ideas, Aesthetic Experience, and the Revolution of Schopenhauer's Great Contradiction", International Studies in Philosophy 19 (1987): 43-53; F. C. White, "Schopenhauer and Platonic Ideas", in: B. Vandenabeele, A Companion to Schopenhauer (Oxford: Basil Blackwell); J. Young, "The Standpoint of Eternity: Schopenhauer on Art", Kant Studien 78 (1987): 424-41; J. Young, Willing and Unwilling. A Study in the Philosophy of Arthur Schopenhauer (Dordrecht: Martinus Nijhoff, 1987), 92-95.

${ }^{20}$ Paul Guyer também sugere essa ideia em "Pleasure and Knowledge in Schopenhauer's Aesthetics", 131, nota 9. [Values of Beauty, 265-88, ver também nota 9]
} 
minucioso de ambas. Assim como em Kant, as Ideias estão relacionadas com a faculdade da imaginação e são entidades que absolutamente não podem ser definidas conceitualmente. Elas formam o tênue limite do que pode ser percebido pelos sentidos: elas transcendem a experiência perceptiva e podem ser "apresentadas" apenas através da criação e apreciação artísticas. São organismos vivos, se desenvolvem e são dotadas de força geradora, desenvolvendo novas representações naquele que compreendeu essas Ideias representações que são "novas no que se refere ao conceito de mesmo nome" ${ }^{21}$. Kant se utiliza das Ideias estéticas no mesmo sentido: elas são inesgotáveis, desenvolvem todos os tipos de representação extra (Nebenvorstellungen), e transmitem um momento (Schwung) à mente $^{22}$. As Ideias estéticas incitam o pensamento, mas não podem ser expressas em palavras ou $\operatorname{conceitos}^{23}$. Formulando de forma técnica: elas são insondáveis e não indemonstráveis como Ideias racionais ${ }^{24}$.

A constante oscilação entre Kant e Platão torna extremamente difícil uma interpretação inequívoca da estética de Schopenhauer. Isso nos alerta contra uma leitura simplista e ingênua, que ignora as rupturas sutis e as tensões dos textos de Schopenhauer. Primeiramente devo argumentar que - a despeito de comentários feitos pelo próprio Schopenhauer - o prazer estético não pode ser reduzido a um prazer negativo produzido por uma libertação do querer, em segundo lugar - novamente em oposição aos comentários do próprio filósofo -, que há elementos em sua descrição de sublime que não podem se harmonizar com sua ideia de que a experiência estética é uma espécie de experiência protoética de satisfação desprovida de vontade que, em última instância, resultaria em um tipo de arrebatamento místico que um ascético ou um santo experienciariam.

\section{Prazer Positivo}

Schopenhauer enfatiza com frequência o caráter negativo do prazer: "dor, sofrimento que inclui todo o querer, privação, necessidade, na verdade todo desejo ou inclinação que são sentidos e experimentados positivamente. Por outro lado, a natureza da satisfação, fruição e felicidade consiste tão somente na remoção de uma privação, no roubar a dor; portanto, estes possuem um efeito negativo" (HN III, 146). É evidente que a natureza do prazer estético, que nasce da percepção de uma Ideia platônica, também é negativa. Isso significa que nos liberta de perturbações, das dores e sofrimentos que acompanham nossas necessidades e desejos. Assim, o prazer estético como que nos anestesia: a contemplação estética alivia o sofrimento e amortece a dor que acompanha a rotina diária atormentada pela vontade ${ }^{25}$.

\footnotetext{
${ }^{21} W W R$ I, $\S 49$, 235: "A Ideia, por outro lado, desenvolve naquele que a apreendeu representações que são novas no que se referem ao conceito de mesmo nome: ela é como um organismo vivo desenvolvendo a si mesmo e dotado de força geradora, e que cria aquilo que não havia sido anteriormente colocado nele."

${ }^{22}$ Ver abaixo, na seção 4, sobre a especificidade do sublime.

${ }^{23}$ Ver I. Kant, Critique of Judgement [KUK], traduzido com introdução por Werner S. Pluhar (Indianapolis: Hacket, 1987), § 49, p. 182: "e por ideia estética quero dizer uma apresentação da imaginação que desperta muita reflexão, mas para a qual não há um pensamento determinado, i.e., não há um conceito determinado que possa ser adequado, portanto nenhuma linguagem pode expressá-lo plenamente e permitir que o compreendamos".

${ }^{24}$ Ver KUK, § 57, I, p. 215: "Penso que podemos chamar ideias estéticas de inexprimíveis apresentações da imaginação, e ideias racionais de indemonstráveis conceitos da razão".

${ }^{25}$ Ver Guyer, "Prazer e Conhecimento na Estética de Schopenhauer", 109: "Mas uma tal consideração puramente negativa dos prazeres de uma forma tão elevada de cognição parece decepcionante, e trata a experiência estética, na verdade, como nada além de um anestésico".
} 
Como observei anteriormente, Schopenhauer argumenta que a percepção estética consiste em duas partes inextricavelmente ligadas: o conhecimento do objeto como Ideia e a autoconsciência, não como indivíduo, mas como puro sujeito do conhecer desprovido de vontade $^{26}$. No entanto, isso ainda não quer dizer que o prazer estético brota de duas fontes diferentes ou que existem dois tipos diferentes de prazer estético, mas apenas que é necessário que duas condições sejam cumpridas para que ocorra o prazer estético. No entanto, Schopenhauer dá um passo além e sugere um quadro mais complicado:

Ademais, veremos que o prazer [Wohlgefallen] produzido pela contemplação do belo nasce dessas duas partes constituintes, às vezes mais de uma do que da outra, dependendo do que seja o objeto de contemplação estética. (WWR I, § 52, 256)

Como nos aponta Guyer, isso indica que a contemplação da Ideia não é apenas a ocasião para um estado de ausência de vontade e serenidade, o qual é prazeroso porque me liberta da dor e do sofrimento que acompanham o querer, mas que a contemplação de Ideias (platônicas) é por si mesma fonte de prazer, o que é, até um certo ponto, independente do prazer negativo que está ligado ao sentimento de libertação dos tormentos da vontade ${ }^{27}$.

Na seção 42 d'O Mundo como Vontade e Representação, Schopenhauer retorna ao elemento positivo quando escreve que "a fonte da apreciação estética se encontrará por vezes na apreensão da Ideia conhecida, e por vezes na bem-aventurança e paz de espírito do puro conhecer livre de todo o querer e, portanto, livre de toda individualidade e da dor que provém dela" (WWR I, $\S 42,212$ ). Isso nos mostra não somente que existem duas fontes distintas de prazer, que podem estar presentes em diferentes graus de contemplação estética, mas também mostra que o prazer, às vezes, se origina da contemplação da Ideia e, às vezes, da alegre serenidade que se experimenta pela libertação das garras do querer. Essa afirmação só fará sentido se as duas fontes de prazer - embora sempre ocorram juntas puderem, até um certo ponto, gerar prazer independentemente uma da outra. Consequentemente, precisamos distinguir duas espécies distintas de prazer que podem ser chamadas de positiva e negativa com base em suas etiologias ${ }^{28}$. Existem duas formas de prazer que não são necessariamente distinguíveis fenomenologicamente, mas que podem ser caracterizadas etiologicamente como dois componentes distintos de uma complexa experiência (estética) que Schopenhauer quer descrever.

A hierarquia de Schopenhauer para as formas de arte em estética inferior ou superior é, em parte, baseada em sua diferenciação etiológica das formas de prazer estético. Beleza natural e as formas de arte "inferiores" estão ligadas ao prazer negativo, com o sentimento de alívio diante da libertação dos desejos da vontade. Mas alguns objetos estéticos são considerados superiores porque geram o prazer positivo que está interligado à contemplação desinteressada de uma Ideia e ao uso específico das faculdades cognitivas: "se animais e seres humanos são objetos de contemplação ou apresentação estética, o usufruto consistirá antes na apreensão objetiva dessas Ideias que são as mais distintas revelações da vontade" ( WWR I, § 42, 212). Essa observação chega a sugerir que libertar-se da vontade e, portanto, do sofrimento, não é o mérito mais crucial da intuição estética. Quanto mais alto a arte superior subir na escala hierárquica das formas estéticas, mais importante será o prazer

\footnotetext{
${ }^{26}$ Ver WWR I, § 38, 195-96. Para o seguinte, ver também Guyer, “Pleasure and Knowledge in Schopenhauer's Aesthetics".

27 Ver Guyer, "Pleasure and Knowledge in Schopenhauer's Aesthetics”, 125. "Esse prazer positivo é, naturalmente, independente da vontade apenas até um certo ponto, uma vez que ambos são inextricavelmente ligados um ao outro."

${ }^{28}$ Ver Guyer, "Pleasure and Knowledge in Schopenhauer's Aesthetics”, 126.
} 
intrínseco da contemplação. Portanto, o prazer estético não pode e não deve ser reduzido a uma satisfação passiva de alívio da dor e do sofrimento. A filosofia de Schopenhauer reconhece o fato de que algumas experiências cognitivamente significativas podem ser intrinsecamente prazerosas enquanto, ao mesmo tempo, nos libertam das dores que acompanham outras experiências ${ }^{29}$.

\section{Variantes do Prazer Estético}

A descrição de Schopenhauer do sentimento sublime nos fornece um segundo elemento importante que lança dúvidas sobre o caráter "propedêutico" da experiência estética (com a completa renúncia ou Verneinung do querer como seu fim último). O desenvolvimento da noção de sublime é inspirado pela Analítica do Sublime de Kant. Schopenhauer muito admirava a análise kantiana do sublime, que chama

de longe a parte mais excelente da Crítica da Faculdade de Julgar. (...) É incomparavelmente mais bem sucedida do que o Belo, e não só nos dá o método geral de investigação, como esse nos dá, mas também uma parte do caminho correto, tanto que, embora não nos ofereça a verdadeira solução para o problema, não deixa de muito se aproximar de fazê-lo. (WWR I, 532)

A teoria schopenhaueriana do sublime está incluída em uma ontologia da vontade irracional, o que não é o caso em Kant; esse fato tem obscurecido com frequência os paralelos notáveis entre as duas teorias.

A seção 39 d'O Mundo como Vontade e Representação oferece uma ótima descrição das diferenças mais relevantes entre o belo e o sublime. Schopenhauer considera a diferença entre os dois sentimentos no contexto da dicotomia ativo/passivo. A Beleza natural, sob o ponto de vista de Schopenhauer, é um exemplo típico de como algo (uma tulipa, uma paisagem ao Sul da França etc.) pode facilmente nos levar a um estado contemplativo desprovido de vontade. Essa transição para a percepção pura ocorre mais facilmente

quando os objetos se acomodam a ela, em outras palavras, quando, pela sua forma ao mesmo tempo múltipla, mas distinta e definida, eles se tornam representações de suas Ideias, nas quais consiste a beleza em sentido objetivo. Acima de tudo, a beleza natural tem essa qualidade, e até mesmo a pessoa mais impassível e apática obtém a partir daí ao menos um prazer estético fugaz. De fato, é notável como o reino vegetal em particular convida à contemplação estética e, por assim dizer, a exige (zur ästhetischen Betrachtung auffordert und sich gleichsam derselben aufdringt). (WWR I, § 39, 200-201)

Schopenhauer conecta essa capacidade do reino vegetal de, sem esforço, arrastar o indivíduo a um estado de pura contemplação estética explicitamente com o sentimento do belo. Apesar de, ou talvez por causa de, sua visão pessimista de mundo, a ideia de uma subjetividade pura e harmônica nunca está muito longe. Em 1812, enquanto esteve em Berlin, o jovem Schopenhauer já havia nomeado a consciência estética como a "melhor consciência” (das bessere Bewusstsein) (ver HN I, 227). Isso oferece uma alternativa para a consciência individual empírica, que está à serviço da vontade e, portanto, sempre acompanhada de dor e agitação. O sentimento do belo promete nos livrar dessa escravidão de querer e sofrer. Assim como o sentimento do belo - o gosto puro - em Kant, o belo é um

${ }^{29}$ Ver Guyer, "Pleasure and Knowledge in Schopenhauer's Aesthetics", 110. 
sentimento de pura serenidade e harmonia. Ao contrário da consciência comum, a consciência estética não é determinada por nenhum interesse individual ou conceito específico. No belo, sentimos a promessa de unidade e pureza desprovidas de vontade. Esse é um estado de contentamento que pode ser comparado à chamada "ataraxia", o estado equilibrado e pacífico que Epicuro descreve como bem maior e como o estado dos deuses. $\mathrm{O}$ predicado "belo" não é aplicado aos objetos, mas apenas à pura "objetividade" da consciência estética (ver WWR I, § 38, 197).

Esse sentimento puro de harmonia e serenidade desprovido de vontade não deve ser confundido com a chamada resignação ou aquietação da vontade, que certamente não são estéticas. O acalmar da vontade de forma consciente ou a "santa" resignação do desejo é, definitivamente, uma saída da vida ou ao menos um esforço para escapar de suas dores. É também um esforço para livrar-se completamente de si mesmo. A contemplação estética, por outro lado, não implica necessariamente uma tentativa de fuga da vida e não tem meramente a função de "quietivo da vontade" - uma função que claramente encontramos no "santo que encontrou a resignação"; a contemplação estética é apenas "um consolo ocasional" (WWR I, § 52, 267) na vida. Quando os desejos são domados na ascese do santo, quando a vontade é suspensa (aufgehoben) ${ }^{30}$, não há mais a possibilidade de um sentimento estético. O asceta luta para se ver livre do querer, enquanto o espectador estético se conforta na vida. James D. Chansky aponta que, se podemos falar em finalidade na conexão com a estética, devemos concluir que "os fins da estética e do asceticismo não são meramente diferentes, mas, em realidade, bastante antagônicos." ${ }^{31}$ Atribuir bruscamente esse ponto de vista a Schopenhauer é apressado, mas é verdade que, para Schopenhauer, na experiência do belo, o querer não é completamente suspenso; consequentemente, o indivíduo não escapa definitivamente das agitações e tormentos da existência. Há apenas a "promessa" sentida dessa completa libertação e pura serenidade ${ }^{22}$ : é como se estivéssemos livres do sofrimento, mas na realidade não estamos. O belo é a sensação de uma paz beatífica e a mais completa felicidade, mas apenas temporariamente, uma vez que ele é, em última instância, vinculado à resposta contingente a um objeto.

Em oposição aos argumentos de, por exemplo, J. E. Atwell e R. Malter ${ }^{33}$,o prazer pelo belo é uma experiência muito mais rica do que sentir-se livre das dores do querer e dos desejos. É também uma descoberta do que possibilita minha existência. Esteticamente adquirimos discernimento das bases do mundo, ou seja, das Ideias platônicas, que são nada menos do que as objetificações diretas da vontade metafísica. Essa experiência não é um êxtase místico que ilumina o olho espiritual de um observador suprassensível, mas uma atitude estética, ou seja, um estado em que a mente está não-conceitualmente consciente da

\footnotetext{
$3^{30}$ Schopenhauer, surpreendentemente, utiliza com frequência o termo hegeliano "aufheben" nesse contexto.

${ }^{31}$ Chansky, "Schopenhauer and Platonic Ideas: a Groundwork for an Aesthetic Metaphysics", 77, n. 1.

${ }^{32}$ Isto evoca a espécie de promessa mencionada no diálogo entre um pintor e um poeta no Timon of Athens de Shakespeare, ato V, cena 1: "Poeta. O que tens agora para apresentar a ele? / Pintor. Por ora nada além de minha visita; mas irei prometer-lhe uma peça excelente. / Poeta. Também devo servi-lo, contar-lhe de um desígnio que vem em sua direção / Pintor. Bom do melhor. Promessas são o ar do tempo; elas abrem os olhos da expectativa. O desempenho é sempre enfadonho para seu ato, mas nos tipos mais simples e diretos de gente, o ato de dizer está deveras fora de moda. Prometer é cortês e elegante; o desempenho é uma espécie de herança ou testamento que mostra uma grande doença de julgamento da parte de quem o faz." (Citado de W. Shakespeare, The Complete Works, A New Edition, editado com introdução e glossário de Peter Alexander [London/Glasgow: Collins, 1992 (1951)], 946). Schopenhauer admirava Shakespeare imensamente. Sören Kierkegaard (bem como Nikolaus Notabene) também cita esse fragmento no volume Forord (1844); ver Vorworte [Prefaces], em Gesammelte Werke, Abt. 11/12, München, 1991, p. 43.

33 J. E. Atwell, "Art as Liberation", 82; R. Malter, Der eine Gedanke: Hinführung zur Philosophie Arthur Schopenhauers (Darmstadt: Wissenschaftliche Buchgesellschaft, 1988), 62.
} 
pureza de seus sentimentos e percepções. Quando uma obra de arte nos diz "Vê aqui, eis a vida!", como escreve Schopenhauer, isso implica que ela comunica para a nossa percepção o que, ao final de contas, é toda a realidade: a evolução dinâmica ou emanação de uma vontade cega e irracional ${ }^{34}$. Ademais, essa espécie peculiar de despertar contemplativo só pode ser experienciada como uma promessa de bem-aventurança. No belo o indivíduo sente, de forma imediata e momentânea, o que ele poderia ter sido caso não fosse o ser desejoso e necessitado que realmente é. Mas esse "momento" dificilmente parece durar: a resposta da obra de arte "é, deste modo, uma imagem fugaz e não um conhecimento universal permanente." (WWR II, 406). Antes mesmo de nos darmos conta, estamos novamente submetidos à cega e sombria urgência que permeia o mundo inteiro. Repentinamente nos tornamos mais uma vez o indivíduo que quer, que se interessa pela existência concreta do objeto percebido.

O sentimento do belo é apenas uma das variantes dos sentimentos estéticos que Schopenhauer discute. O sentimento do sublime é outra importante variante da experiência estética. Voltamo-nos agora para a análise de Schopenhauer desse sentimento.

\section{A Especificidade do Sublime}

Assim como Kant, Schopenhauer claramente distingue o sentimento do sublime do sentimento do belo. Definitivamente não é uma "subclasse" do belo, como pensa Bryan Magee ${ }^{35}$. O sublime está relacionado a um esforço imenso e consciente da parte do sujeito.

Com o sublime, aquele estado de puro conhecer é obtido, em primeiro lugar, por um violento e consciente desprender-se das relações do objeto com a vontade que são conhecidas como desfavoráveis, por uma livre exaltação acompanhada da consciência para além da vontade e do conhecimento que se vincula a ela. (WWR I, § 39, 202)

A especificidade do sentimento sublime consiste no esforço violento e consciente exigido do sujeito para descartar as conexões comuns da vontade e explicitamente manter (beharren) um estado mental elevado. A elevação não é uma vitória facilmente alcançada do puro sujeito do conhecer sobre o indivíduo do querer empírico, mas, sim, um estado de absoluta tensão, que não apenas deve ser adquirido conscientemente, mas também mantido. No belo, o estado de pura contemplação é alcançado e mantido sem maiores dificuldades. É mérito de Schopenhauer reconhecer a distinção entre as variantes ativa e passiva do sentimento estético e desenvolvê-la como uma distinção crucial em sua teoria.

Ainda assim, o sentimento sublime é um tema muito complexo, que não pode ser caracterizado apenas com base no critério ativo/passivo. No § 39 d'O Mundo como Vontade e Representação, Schopenhauer, de forma bastante dramática, fornece uma visão geral de algumas transições graduais que vão do belo ao sublime, o que esclarece diversas distinções e níveis, sutis, mas importantes, do sublime (ver WWR I, § 39, 203-207). Quando, por exemplo, na intensidade do inverno, o sol poente ilumina os montes de pedra de uma construção sem aquecê-las, isso pode mover-nos a um estado de pura contemplação estética. Uma vez que esse humor é acompanhado de uma suave lembrança da falta de calor

\footnotetext{
34 Ver WWR II, 406: "Assim, para a intuição, toda a obra de arte responde essa pergunta, cada pintura, cada estátua, cada poema, cada cena sobre o palco.... Assim, todas as outras artes exibem juntas, diante do perquiridor, uma imagem intuitiva e dizem: 'Vê aqui, eis a vida!'

35 Magee, The Philosophy of Schopenhauer, 164: “E ele segue utilizando o termo kantiano 'o sublime' para uma subclasse do belo."
} 
dos raios de sol e uma vez que eles não têm o poder de fortalecer a vida, uma certa transcendência da vontade e um leve desafio (leise Aufforderung) para persistir no puro conhecer se faz necessário. Isso nada mais é do que o mais tênue vestígio (schwächste Anhauch) do sublime (ver WWR I, § 39, 203). Mas quando o homem se encontra em uma área abandonada, com árvores e plantas em um ar completamente parado, sem animais, sem pessoas, sem o movimento de massas de água e no mais completo silêncio, será preciso muito mais empenho para proteger-se contra o ameaçador sentimento de tédio e contemplar a cena desinteressadamente. Schopenhauer chama tal situação de um caso de sublime em um baixo grau, o qual ficará mais intenso quando imaginamos a mesma região sem as plantas, somente com rochas nuas. Nesse caso, a vontade não encontra nenhum objeto para satisfazer-se e entra em verdadeiro pânico por conta da completa ausência de vida orgânica que é indispensável para a subsistência do indivíduo. O deserto se torna assustador, e nosso humor se torna trágico. Naturalmente, é necessário um maior esforço para retirar-se dos interesses do querer, mas, uma vez bem sucedido em persistir no estado de pura contemplação, fica-se claramente consciente do sublime ${ }^{36}$.

Schopenhauer frequentemente parece hesitar entre a abordagem empírica e a transcendental: outras passagens cruciais apontam que o sentimento do sublime difere do sentimento do belo não apenas quantitativamente mas fundamentalmente e, como em Kant, qualitativamente. Uma das características mais importantes dos exemplos mais claros de sublime é o fato de que ele é "acompanhado de uma constante reminiscência da vontade, no entanto não se trata do querer do indivíduo, como o medo ou o desejo, mas do querer humano no geral, na medida em que é expresso universalmente através de sua objetividade, o corpo humano". (WWR I, § 39, 202). A palavra "constante" (einer steten Erinnerung) é especialmente importante aqui: a vontade continua permanentemente presente na consciência. É esse o caso enquanto o sentimento de sublime estiver presente, isto é, enquanto o estado de violenta tensão é mantido. O sublime, que pode ocorrer em graus distintos é, portanto, tipicamente diferente do belo por conta da reminiscência permanente e incessante da vontade humana e do corpo humano, cujos vestígios permanecem presentes na mente como um desprazer, e enquanto o sentimento sublime persistir.

Schopenhauer não chega a explicar a condição dessa reminiscência, mas ele argumenta que não se trata de uma reminiscência do querer do indivíduo, medo ou desejo. É uma lembrança do querer humano em geral, pois "se um ato único da vontade entrasse na consciência através de uma real aflição pessoal e do perigo oferecido pelo objeto, a vontade individual, desse modo afetada, mais uma vez estaria em vantagem. A paz da contemplação se tornaria impossível, a impressão do sublime seria perdida” (WWR I, § 39, 202). Na ocorrência de uma real ansiedade pessoal, não contemplaríamos a ameaçadora e opressora cena, mas, sim, tentaríamos nos salvar. Qualquer lembrança do querer individual, qualquer afecção direta, causaria ansiedade e aniquilaria o sentimento sublime. Quando a vontade individual é tocada, o sujeito acaba por se encontrar no contrário do sublime: o fascinante e atraente (das Reizende), que não é de modo algum estético (ver WWR I, §40, 207). No fascinante, a mente é completamente passiva: um prazer meramente sensual (Genuss) e não apreciação (Wohlgefallen) ou alegria (Freude). O atraente "retira o observador da pura contemplação" que é necessária à intuição estética, e, portanto, "não permanece puro sujeito do conhecer, mas se torna o carente e dependente sujeito do querer" (WWR I, § 40, 207). Ao contrário do atraente, o sublime é um sentimento estético puro. Mas é um sentimento

$3^{6}$ Ver WWR I, § 39, 204: “A exaltação ao conhecimento puro se dá a partir de uma emancipação decidida dos interesses da vontade, e ao persistir no estado de conhecimento puro, o sentimento sublime aparece distintamente". 
estético que, diferentemente do belo, ainda é acompanhado por uma permanente reminiscência da vontade humana. $\mathrm{O}$ que isso poderia significar?

Uma ansiedade real não pode ocorrer porque isso daria origem a uma forte preocupação individual pelo lado do sujeito. Mas, ao contrário de Kant, que alega que "não podemos de modo algum julgar no sublime da natureza se estivermos com medo" (KUK, § 28, p. 120)37, Schopenhauer supreendentemente leva a ameaça real em consideração no caso do sublime (ver $H N$ II, 289; cf. $K U K, \S 28$ ). O sujeito (e sua vontade) é verdadeiramente assustado e até mesmo ameaçado, e está claramente ciente da natureza hostil e violenta do objeto. Ainda assim não procura escapar. Nós não experimentamos nenhuma resposta afetiva que seja irreconciliável com uma verdadeira contemplação estética.

A natureza em movimentos tempestuosos; semiescuridão através de nuvens de trovão negras e ameaçadoras; penhascos suspensos imensos, nus, bloqueando a visão por seu entrelaçamento; massas de água correndo e espumando; completo deserto; o lamento do vento varrendo através das ravinas. Nossa dependência, nossa luta contra a natureza hostil, nossa vontade que nisso é rompida, agora aparece claramente diante de nossos olhos. No entanto, enquanto uma aflição pessoal não tomar a frente, permanecemos em contemplação estética, o puro sujeito do conhecer encara por através dessa luta da natureza.... (WWR I, § 39, 204).

Um dos aspectos cruciais de uma resposta sublime parece ser uma espécie de dissociação ou não-efetivação de nossos afetos pessoais ou de respostas emocionais individuais. Isso explica porque também Kant chama expressamente o entusiasmo dos espectadores (e não dos agitadores) da revolução francesa de efeito sublime ${ }^{8}$. Os distantes espectadores não podem ser suspeitos de nenhum interesse empírico: isso garante a natureza puramente estética de seus sentimentos ${ }^{39}$. No sublime é possível sentir um prazer desinteressado naquilo que seja cruel ou ameaçador. Mas a reminiscência da vontade permanece vividamente presente em nossas mentes. Sentimo-nos ameaçados ou inquietos, mas experienciamos esses sentimentos de forma impessoal. $O$ que sentimos não parece pertencer ao nosso próprio mundo particular de emoções. Tornamo-nos, por assim dizer, um sujeito desprovido de si mesmo - como escreve Oscar Wilde, em The Critic as Artist: "me sinto como se eu estivesse chorando por pecados que nunca cometi, e em luto por tragédias que não são minhas." 40

Alguns elementos no trabalho de Schopenhauer sugerem que a preocupação central do autor seria o triunfo do puro conhecer sobre o querer. Schopenhauer conecta frequentemente o sublime a um senso de elevação ou exaltação a partir de um sujeito passivo que é submetido à vontade e torna-se um puro sujeito que ativa e espontaneamente contempla as essências ideais da vontade. No entanto, o sentimento sublime é muito mais específico: não se trata apenas de um sentimento acompanhado da elevação do sujeito por sobre a vontade empírica - tal elevação também acontece no caso do belo - mas uma

\footnotetext{
37 Ver também KUK, 121: "precisamos nos encontrar em segurança para sentirmos essa estimulante apreciação, de modo que (como pode parecer), uma vez que o perigo não é genuíno, a sublimidade de nossa habilidade intelectual possa também não ser genuína”.

${ }^{38}$ KUK, § 29, Observação Geral, 132: "O entusiasmo é esteticamente sublime, no entanto, porque é uma tensão de nossas forças por ideias que dão à mente um impulso [welche dem Gemüthe einen Schwung geben] cujos efeitos são mais poderosos e duradouros do que o impulso produzido por representações dos sentidos."

39 Ver J.-F. Lyotard, Le différend (Paris: Minuit, 1983), 241. Ver também J.-F. Lyotard, L'enthousiasme. La critique kantienne de l'histoire (Paris: Galilée, 1986), cap. 3.

${ }^{40}$ O. Wilde, "The Critic as Artist. A Dialogue in two parts", Collected Works (Ware: Wordsworth Editions, 1997), 823 .
} 
experiência estética que dá origem a uma compreensão da natureza dupla de nossa consciência (Duplizität seines Bewusstseins) ${ }^{41}$, Nesse sentido não pode haver continuidade do belo ao sublime: o extremamente belo não é, necessariamente, um traço tênue do sublime. O belo é um sentimento harmonioso e sereno. O sublime é violento e paradoxal. Quando se torna possível, através de um imenso esforço, experienciar o irresistível e hostil objeto tanto como ameaçador quanto como prazeroso, o sublime claramente ocorre. Schopenhauer escreve:

Simultaneamente, ele se sente como um indivíduo, como o frágil fenômeno da vontade, no qual o menor toque dessas forças pode aniquilar, desamparado diante da poderosa natureza, dependente, abandonado ao acaso, um nada desvanecendo em face a forças estupendas; e ele também se sente como o eterno, sereno sujeito do conhecer, que como condição de todo objeto é o sustentáculo do mundo inteiro.... Essa é toda a impressão do sublime. Aqui ela é causada pela visão de um poder além de qualquer comparação, superior ao indivíduo e que o ameaça com a destruição." (WWR I, §39, 204-205)

Essa passagem revela que o sentimento sublime é uma verdadeira experiência de contraste - não é meramente um triunfante conquistar da vontade, menos ainda "uma contradição da vastidão do ser no conteúdo da consciência do eu numênico" e "um movimento de egoísmo cósmico", como defende Julian Young ${ }^{42}$. A experiência de contraste ("Simultaneamente ele se sente ...") atesta uma tensão irremovível ou fissura em nosso Gemüt. Essa tensão irremovível e paradoxal entre querer e conhecer, que caracteriza nossa subjetividade - essa oscilação contínua entre desejos empíricos e pura contemplação - pode ser experienciada em graus diversos, mas não pode jamais ser definitivamente solucionada. O sublime (das Erhabene) é o sentimento estético de elevação (Erhebung) sobre a individualidade empírica, mas essa exaltação violenta nunca será verdadeiramente sentida como sublimidade (Erhabenheit): a vontade não pode ser definitivamente domada (Velle non discitur) ${ }^{43}$. Podemos ter essa impressão quanto ao sublime, mas será sempre uma impressão ilusória: o sublime é um sentimento ambivalente de prazer e dor ao mesmo tempo. Ao contrário do belo, que ainda pode prometer pura e completa harmonia, o sublime é a mais clara experiência possível da lacuna intransponível entre o querer e o contemplar que caracteriza a subjetividade humana. Que possamos de fato desfrutar disso esteticamente é, talvez, o verdadeiro "milagre par excellence ${ }^{44}$.

\section{Referências}

\section{A. L. Cothey, The Nature of Art, Londres: Routledge, 1990.}

\footnotetext{
${ }^{41}$ Ver WWR I, § 39, 204: "Então, no imperturbável espectador dessa cena, a duplicidade de sua consciência atinge o mais elevado grau. Ele se sente simultaneamente como indivíduo ... e se sente como o eterno e sereno sujeito do conhecer."

42 J. Young, "Death and Transfiguration: Kant, Schopenhauer and Heidegger on the Sublime", Inquiry 48 (2005): 140. Young até mesmo (e injustamente) argumenta na mesma página que a teoria do sublime de Schopenhauer "ilustra claramente o caráter egoísta - ou, mais exatamente, solipsista - do pensamento de Schopenhauer."

43 Essa é uma frase de Sêneca (Epistulae, 81 14), frequentemente citada por Schopenhauer.

44 Para uma análise mais detalhada da experiência estética, também em relação com outros gêneros artísticos, veja meu The Blossom of Life, também meu "Schopenhauer's View of Aesthetic Experience", in: B. Vandenabeele, ed., A Companion to Schopenhauer (Oxford: Basil Blackwell).
} 
BM: On the Basis of Morality, trad. E. F. J. Payne, with an introduction by David E. Cartwright Providence: Berghahn Books, 1995.

CHANSKY J. D., Schopenhauer and Platonic Ideas: a Groundwork for an Aesthetic Metaphysics In: E. von der Luft (ed.) Schopenhauer: New Essays in Honor of his 2ooth Birthday, 67-81 Lewiston, NY: Edwin Mellen Press, 1988.

DICKIE, G. Introduction to Aesthetics. An Analytic Approach New York/Oxford: Oxford University Press, 1997.

EAGLETON, T. The Ideology of the Aesthetic. Oxford: Blackwell, 1990.

FR: The Fourfold Root of the Principle of Sufficient Reason, trad. E. F. J. Payne, La Salle: Open Court, 1997.

GARDINER, P. Consciência e compreensão da Ideia nos e através dos fenômenos individuais da experiência cotidiana. In: Gardiner, P. Schopenhauer, Harmondsworth: Penguin Books, 1971.

GUYER, P. Pleasure and Knowledge in Schopenhauer's Aesthetics. In: Guyer, P. Schopenhauer, Philosophy and the Arts, New York, Cambridge University Press, 1996.

HAMLYN, D.W. Schopenhauer. London: Routledge and Keagan Paul, 1980.

HN I, II, III, IV, V: Der handschriftliche Nachlass, 5 Bäude, ed. A. Hübscher (Frankfurt am Main: Waldemar Kramer, 1975-1996.

J. E. ATWELL, "Art as Liberation”, 82; R. Malter, Der eine Gedanke: Hinführung zur Philosophie Arthur Schopenhauers Darmstadt: Wissenschaftliche Buchgesellschaft, 1988.

KANT, I. Critique of Judgement [KUK], Trad. Werner S. Pluhar, Indianapolis: Hacket, 1987.

LYOTARD, F. Le différend (Paris: Minuit, 1983), 241.

LYOTARD, J.-F. L'enthousiasme. La critique kantienne de l'histoire Paris: Galilée, 1986.

MAGEE, The Philosophy of Schopenhauer

NEYMEYR, B. Ästhetische Autonomie als Abnormität. Berlin/New York: Walter de Gruyter, 1996.

PHILONENKO, A. Une philosophie de la tragédieç. Paris: Vrin, 1980.

PP I, II: Parerga and Paralipomena, 2 vols., trad. E. F. J. Payne Oxford: Clarendon Press, 1974-

Schöndorf, Der Leib im Denken Schopenhauers und Fichtes, München: Johannes Berchmans, 1982.

WILDE, O. The Critic as Artist. A Dialogue in two parts. In: Wilde, O. Collected Works Ware: Wordsworth Editions, 1997.

WWR I, II: The World as Will and Representation, 2 vols., trad. E. F. J. Payne, New York: Dover Publications, 1966. 